\title{
ГИДРОФИЗИЧЕСКИЕ ПРОЦЕССЫ
}

УДК. 551.464.3

\section{ОСОБЕННОСТИ ВЕРТИКАЛЬНОГО ВОДООБМЕНА ВОД КАСПИЙСКОГО МОРЯ НА ОСНОВЕ РАСПРЕДЕЛЕНИЯ ПРЕХОДЯЩИХ ТРАССЕРОВ}

\author{
(C) 2019 г. В. С. Брезгунов ${ }^{1, *}$ \\ ${ }^{1}$ Институт водных проблем РАН \\ Россия 119991 Москва \\ *e-mail: brez@iwp.ru \\ Поступила в редакцию 01.02.2018 г. \\ После доработки 19.02.2019 г. \\ Принята к публикации 11.04.2019 г.
}

\begin{abstract}
Проведен анализ достоверности разных сценариев формирования вертикальной структуры вод Каспийского моря, полученных по результатам распределения преходящих трассеров (CFC-11, CFC-12, ${ }^{3} \mathrm{H}$ и $\left.{ }^{3} \mathrm{He}\right)$ на глубоководных станциях Среднего и Южного Каспия в рамках проведенных международных комплексных изотопно-геохимических исследований в период максимального подъема уровня моря в 1995-1996 гг. С учетом доступных гидрометеорологических данных и особенностей датирования вод с помощью используемых преходящих трассеров сделан вывод, что после крупномасштабной гравитационной конвекции в Среднем Каспии, вызванной аномальным охлаждением поверхностных вод в Северном Каспии в конце зимы 1976 г., сформировалась структура водных масс, исключавшая вентиляцию глубинных вод в Среднем и Южном Каспии до середины 1990-х гг.
\end{abstract}

Ключевые слова: Каспийское море, вертикальный водообмен, преходящие трассеры.

DOI: $10.31857 / \mathrm{S} 0321-0596465496-502$

Начавшееся в середине 1970-х гг. повышение уровня Каспийского моря привлекло внимание исследователей к проблеме многолетней изменчивости гидрологического режима моря в связи с вариациями климата, в частности к изменению вертикальной структуры вод и связанной с ней вентиляцией глубинных вод Каспийского моря [4, 6-8].

На основе анализа изменчивости многолетней вертикальной термохалинной структуры вод Каспийского моря выявлены два типа гидрологических режимов, определяющих вертикальную плотностную устойчивость вод в глубинных областях Каспийского моря. В периоды увеличения речного стока и связанного с ним повышения уровня моря вертикальный водообмен замедляется вплоть до полного прекращения вентиляции глубинных вод. Именно такое состояние характерно для Каспийского моря в период подъема его уровня с середины 1970-х до середины 1990-х гг. [6]. С другой стороны, активный водообмен поверхностных и глубинных вод имеет место в периоды низкого стояния уровня моря, особенно в тех случаях, когда уменьшение речного стока сочетается с суровыми зимами.

Проведенные в 1994-1996 гг. комплексные исследования Каспийского моря позволили охарактеризовать картину распределения океанографических, изотопных и гидрохимических параметров на стадии стабилизации уровня моря после почти 20-летнего периода его подъема в связи с особенностями вертикального водообмена моря в этот период.

В первой публикации по результатам этих исследований [11], содержащей интерпретации исключительно изотопных данных, отмечается значимое различие содержания ${ }^{18} \mathrm{O}$ в поверхностных и глубинных водах основной акватории Каспийского моря. Это позволило авторам сделать вывод, что глубоководная часть моря сформировалась во время низкого стояния его

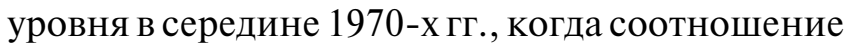
составляющих водного баланса моря (приток пресных вод - испарение) было иным, нежели в период опробования. Оцененный по распределению трития и гелия-3 возраст водных 
масс, лежащих ниже горизонта 300 м в Среднем и Южном Каспии, составляет 20-25 лет [11].

Более детальное рассмотрение результатов изотопного анализа $[1,9]$ позволило получить дополнительную информацию об особенностях гидрологической структуры и о генезисе глубинных водных масс Среднего и Южного Каспия. Сопоставление параметров уравнений линейной зависимости изотопного состава кислорода от солености $\left(\delta^{18} \mathrm{O}-S\right)$ в разных водных массах моря, опробованных в 1995 г., с учетом изотопных эффектов при фазовых переходах воды и опреснении речными водами, дали возможность сделать вывод, что на $S$ глубинных водных масс Среднего Каспия (ниже горизонта 100 м) заметно влияли процессы ледообразования. По результатам анализа диаграммы $\delta^{18} \mathrm{O}-S$ средних значений этих параметров для четырех дифференцированных по глубине слоев Каспийского моря глубинные воды Южного Каспия - смесь глубинных вод Среднего Каспия с подповерхностными водами моря [9].

Наиболее обстоятельно вопрос об особенностях вертикального водообмена вод Каспийского моря на основе анализа распределения традиционных океанографических параметров и преходящих, неконсервативных во времени трассеров (“transient tracers") в воде моря в рамках проведенных исследований 1995-1996 гг. рассмотрен в работе [14]. Кроме ${ }^{3} \mathrm{H}$ и ${ }^{3} \mathrm{He}$, для оценки возраста глубинных вод авторами этой работы использовались результаты определения концентраций растворенных в воде хлорфторуглеродов (CFC-11 и СFC-12) и атмосферных благородных газов.

Хлорфторуглероды (фреоны) - высоколетучие, химически инертные у земной поверхности вешества, широко применяемые в производстве и быту в качестве хладагентов (холодильники, кондиционеры, рефрижераторы), пенообразователей и распылителей. Интенсивное производство фреонов началось в конце 1920-х гг. и было прекращено в конце 1980-х гг., поскольку поступление фреонов в атмосферу - один из самых действенных факторов разрушения ее озонового слоя. Парциальное давление фреонов в атмосфере быстро возрастало с начала 1930-х до середины 1990-х гг. Временная шкала этого роста надежно задокументирована [10]. С начала 1950-х до середины 1990-х гг. количество фреонов в земной атмосфере ежегодно увеличивалось на 8-9\%. Атмосфера - единственный источник поступления хлорфторуглеродов в морскую среду и континентальные водоемы.
При этом предполагается, что концентрация растворенного в воде хлорфторуглерода находится в равновесии с его парциальным давлением в атмосфере.

Наиболее распространенные хлорфторуглероды CFC-11 и CFC-12 ( $\mathrm{CCl}_{3} \mathrm{~F}$ и $\left.\mathrm{CCl}_{2} \mathrm{~F}_{2}\right)$ практически не гидролизуются в тех открытых водоемах, где они используются в качестве преходящих трассеров, поскольку анализируемые образцы воды содержат измеримые количества растворенного кислорода. Такие природные водоемы не являются стоком для этих фреонов, а представляют собой лишь резервуары, из которых фреоны опять поступают в атмосферу.

Сопоставление измеренных концентраций хлорфторуглеродов в воде океанов, морей и глубоководных озер с хронологической шкалой изменения парциального давления их в атмосфере дает принципиальную возможность определить время последнего контакта водных образцов с атмосферой. Надежное датирование этого события требует данных по температуре воды для оценки равновесной концентрации фреона в поверхностном слое воды.

Одновременное определение концентраций ${ }^{3} \mathrm{H}$ и ${ }^{3} \mathrm{He}$ также позволяет оценить время поступления вод из поверхностного слоя в глубинные слои водоемов. В природные водоемы ${ }^{3} \mathrm{H}$ поступает с атмосферными осадками, речным стоком и в результате влагообмена на поверхности водоема. Опускаясь в глубинные слои, ${ }^{3} \mathrm{H}$ распадается с образованием дочернего продукта $-{ }^{3} \mathrm{He}$. Сопоставление концентраций ${ }^{3} \mathrm{H}$ и радиогенного ${ }^{3} \mathrm{He}$ в водных образцах позволяет определить время переноса воды из поверхностного в глубинные слои. Идентификация радиогенного ${ }^{3} \mathrm{He}$ в воде проводится с учетом его природных источников - атмосферного и мантийного. Таким образом, глубоководные водоемы - область стока для ${ }^{3} \mathrm{H}$, в то время как поток ${ }^{3}$ Не приводит к увеличению его содержания в глубинных водах по сравнению с поверхностными.

Оценка “кажущегося” (“apparent”) возраста глубинных вод на основе распределения CFC11, CFC-12, ${ }^{3} \mathrm{H}$ и ${ }^{3} \mathrm{He}$ использовалась при исследовании механизма вентиляции водной толщи в морской среде и крупных озерах $[15,16]$.

Интерпретация результатов вертикального распределения СFC-11, CFC-12, ${ }^{3} \mathrm{H}$ и ${ }^{3} \mathrm{He}$ на станциях Среднего и Южного Каспия в 19951996 гг. в районе максимальных глубин позволила авторам работы [14] сделать оригиналь- 
ные, но неоднозначные выводы о характере вертикального водообмена в Каспийском море.

Возрастные характеристики водных масс Среднего и Южного Каспия и анализ вертикальной устойчивости водной толщи Каспийского моря в конце лета 1995 г. позволили авторам [14] предположить, что глубоководный обмен в море может происходить в результате прерывистого процесса с редким крупномасштабным конвективным перемешиванием. Оцененное по содержанию преходящих трассеров время пребывания воды ниже глубины 500 м в Среднем и Южном Каспии дали возможность авторам [14] сделать вывод, что последнее такое событие произошло в 1976 г. - незадолго до того, как начался подъем уровня Каспийского моря. После этого вертикальный водообмен в море сушественно замедлился. При этом вентиляция глубинных вод практически отсутствовала, о чем свидетельствует однородное по вертикали содержание преходящих трассеров в водной массе глубже 500 м. Оцененное авторами [14] по концентрациям CFC-12, ${ }^{3} \mathrm{H}$ и ${ }^{3} \mathrm{He}$ среднее время пребывания воды в слое ниже глубины 500 м относительно сезонного смешанного слоя в 1995-1996 гг. в Среднем и Южном Каспии лежит в диапазоне 17-21 года. В целом выводы этой работы совпадают с выводами [6].

Авторы [14] рассматривают два сценария, которые могут привести к крупномасштабному вертикальному водообмену в Среднем и Южном Каспии.

Первый сценарий предполагает развитие вертикальной конвекции, достигающей дна, в Среднем Каспии в особо суровые зимы на границе кромки льда при формировании аномально плотных вод за счет дополнительного осолонения при ледообразовании. При этом поступление “молодых" вод в глубинные слои Среднего Каспия сопровождается вентиляцией глубинных вод Южного Каспия за счет перетока “старых" среднекаспийских глубинных и промежуточных вод через Апшеронский порог. Этот сценарий не объясняет того факта, что кажущийся возраст глубинных вод, оцененный на основе распределения CFC-11, CFC-12, ${ }^{3} \mathrm{H}$ и ${ }^{3} \mathrm{He}$, в Среднем и Южном Каспии практически одинаков.

Это побудило авторов [14] предположить, что возможен второй сценарий - одновременное крупномасштабное вертикальное перемешивание вод в обеих котловинах в 1976 г. с поступлением “молодых" поверхностных вод в глубинные слои без заметного водообмена между котловинами.

Мы попытаемся оценить достоверность этих сценариев с учетом доступных гидрометеорологических данных и особенностей датирования вод с помощью используемых преходящих трассеров.

В первую очередь рассмотрим, в какой мере гидрометеорологические условия в Северном Каспии в 1976 г. соответствовали первому сценарию вертикального водообмена - развитию крупномасштабной гравитационной конвекции на исходе зимы. На рис. 1 представлены среднемесячные значения температуры поверхностного слоя воды в январе, феврале и марте в 1970-е гг. на ст. Тюлений в Северном Каспии [3]. Зримо выделяется аномально низкая температура воды в марте 1976 г. по сравнению со смежными годами на фоне малой временной изменчивости температуры воды в январе и феврале.

Такова же картина изменения среднемесячных значений температуры воды и на другой станции Северного Каспия - Лагань [3].

По существу, изменение среднемесячных значений температуры воды в марте в Северном Каспии в период 1972-1980 гг. отражает соответствующий годовой ход среднемесячной температуры воздуха в Астрахани, для которого также характерна аномально низкая температура в марте 1976 г. (рис. 2) [2]. Отметим, что в первую декаду марта средняя температура в Астрахани в 1976 г. составляла $-7.5^{\circ} \mathrm{C}$. Аномально низка среднемесячная температура воздуха в марте 1976 г. в Махачкале $-+1.4^{\circ} \mathrm{C}$ при среднемесячном значении за базовый период $1961-1990$ гг. $+4.6^{\circ} \mathrm{C}[2]$.

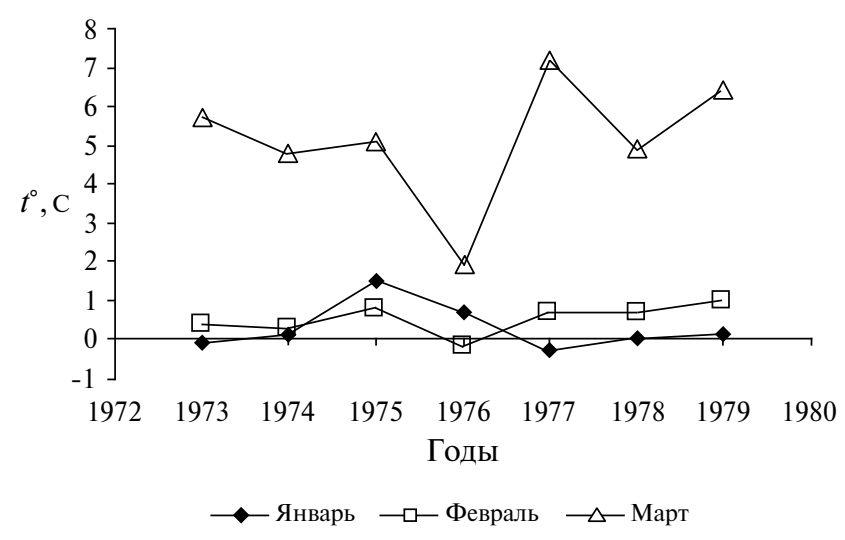

Рис. 1. Изменение среднемесячных температур воды на ст. Тюлений, Северный Каспий [3]. 


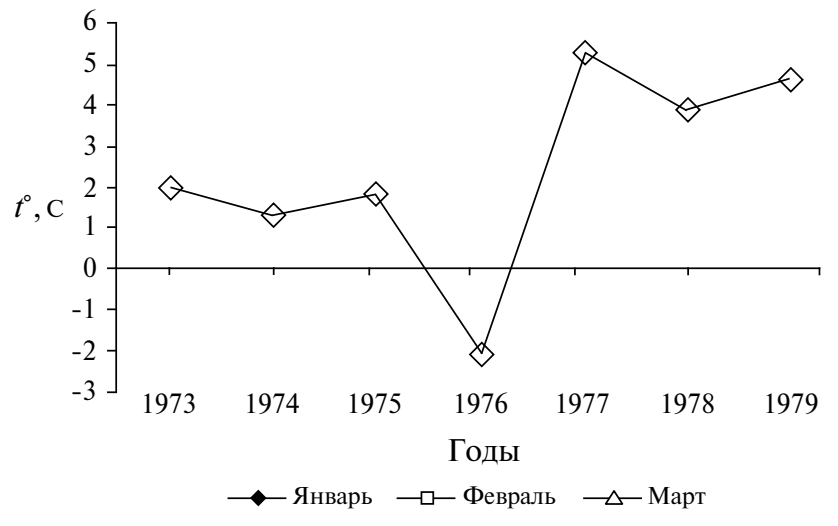

Рис. 2. Изменение среднемесячных температур воздуха марта в Астрахани в 1973-1979 гг.

Полагаем, что приведенные данные - достаточно убедительное свидетельство возможности реализации крупномасштабного вертикального водообмена в Среднем Каспии, для которого, по мнению авторов, определяющий фактор - отрицательная температура воздуха в марте 1976 г. в районе Северного и Среднего Каспия, способствующая дополнительному осолонению вод у кромки ледяного покрова. В пользу этого сценария также свидетельствуют данные о повышенном содержании растворенного кислорода в глубинных водах Среднего Каспия в 1976 г., которые авторы [14] приводят, ссылаясь на работу [12]. По Южному Каспию таких данных нет.

Годовой ход среднемесячных значений температуры поверхностной воды в Среднем и Южном Каспии существенно отличается от того, что наблюдается в Северном Каспии (рис. 3,4$)$. Изменчивость среднемесячной температуры воды в марте на станциях Среднего

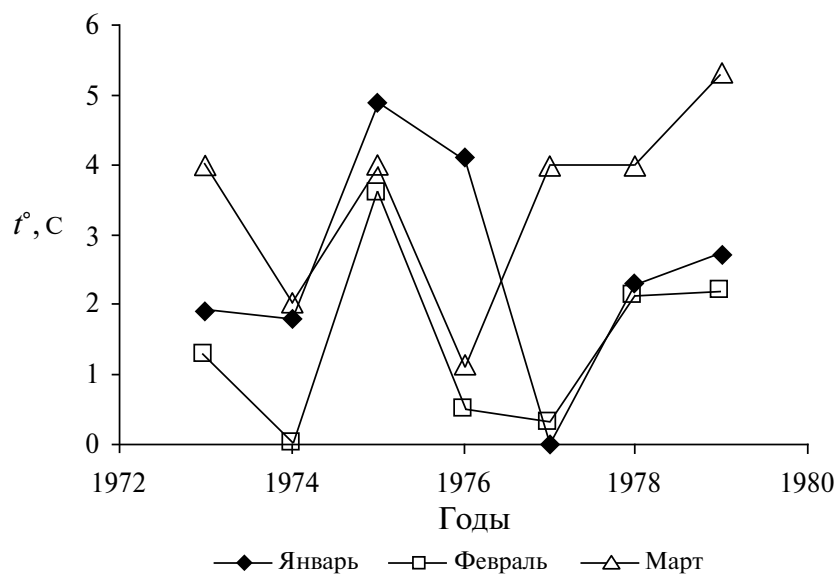

Рис. 3. Изменение среднемесячных температур воды на ст. Изберг, Средний Каспий в 1973-1979 гг. [3].

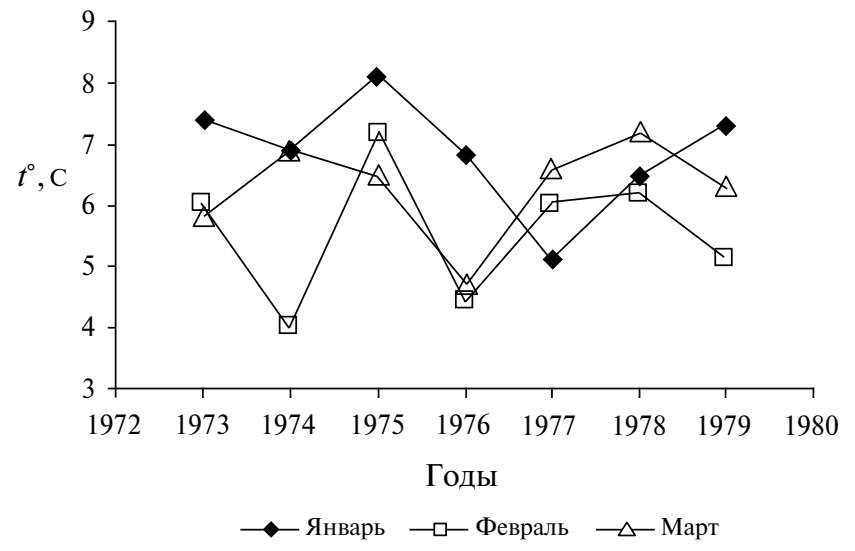

Рис. 4. Изменение среднемесячных значений температуры воды на ст. Нефтяные Камни, Южный Каспий в 1973-1979 гг. [3].

и Южного Каспия не выглядит аномальной на фоне изменчивости среднемесячной январской и февральской температуры воды в период 1973-1980 гг.

Как упоминалось ранее, основной довод в пользу второго сценария - практическое совпадение возраста глубинных вод (ниже 500 м) Среднего и Южного Каспия, в то время как при реализации первого сценария возраст глубинных вод Южного Каспия должен превышать соответствующий возраст вод Среднего Каспия, поскольку в этом случае в Южный Каспий перетекают более “старые" воды из Среднего Каспия. В связи с этим рассмотрим особенности датирований вод с помощью преходящих трассеров.

Оценка возраста вод этим методом предполагает, что единственный источник поступления трассеров в морскую среду - атмосфера, после чего не должно быть нового контакта с атмосферой и взаимодействия с водами иного происхождения. При глубинном водообмене в Южном Каспии по первому сценарию этот критерий не выдерживается. В этом случае в глубинные слои поступают не только локальные поверхностные воды в результате зимнего охлаждения, но и среднекаспийские воды с совершенно иной историей пребывания в них трассеров. Подъем и перетекание среднекаспийских вод через Апшеронский порог в Южный Каспий сопровождается турбулентным перемешиванием вод разных горизонтов, имеющих разную температуру, соленость и содержание растворенных газов. Этот процесс поразному распределяет трассеры при попадании в слой зимней конвекции. 
Содержание Не в глубинных водах значимо превышает его содержание в поверхностном слое, поскольку терригенный гелий - основной источник этого элемента в морской среде. Попадая в поверхностные горизонты, глубинные воды Среднего Каспия теряют Не, так как здесь его содержание контролируется равновесной растворимостью атмосферного Не. Этот процесс сопровождается неконтролируемыми потерями радиогенного ${ }^{3} \mathrm{He}$, поскольку ${ }^{3} \mathrm{He}$ менее растворим в морской воде в равновесных условиях, чем основной изотоп этого элемента $-{ }^{4} \mathrm{He} \mathrm{[17],} \mathrm{что} \mathrm{приводит} \mathrm{к} \mathrm{обо-}$ гащению легким изотопом газовой фазы. Концентрация ${ }^{3} \mathrm{H}$ в поверхностном слое в процессе перетока вод через Апшеронский порог по первому сценарию меняется только в процессе перемешивания вод разных горизонтов. Таким образом, можно утверждать, что перетекание глубинных вод Среднего Каспия в Южный Каспий происходит без потери ${ }^{3} \mathrm{H}$ и с уменьшением содержания радиогенного ${ }^{3} \mathrm{He}$. Это, в свою очередь, ставит под сомнение корректность оценки возраста вод в Южном Каспии с помощью данных трассеров. Оценка возраста глубинных вод Южного Каспия, основанная на существовании единственного источника поступления трассера в водоем, в этом случае некорректна.

Достоверность сценариев крупномасштабного вертикального водообмена может быть оценена на основе имеющихся в литературе данных о содержании ${ }^{3} \mathrm{H}$ в поверхностных водах Каспийского моря. В работе [5] на основе собственных определений содержания ${ }^{3} \mathrm{H}$ в поверхностных водах Среднего Каспия в 19751977 гг. и результатов режимных наблюдений за концентрацией ${ }^{3} \mathrm{H}$ в поверхностной воде Южного Каспия с 1960 по 1970 г. [13] выведена зависимость, описывающая уменьшение концентрации ${ }^{3} \mathrm{H}$ в поверхностной воде Каспийского моря в период с1966 по 1977 г.

$$
C_{\text {тр }}=159.2 \mathrm{e}^{-0,129 t}(r=0.94),
$$

$C_{\text {тр }}-$ концентрация ${ }^{3} \mathrm{H}$ через период времени $t$ (годы), в 1966 г. при этом $t=0$.

В соответствии с (1) концентрация ${ }^{3} \mathrm{H}$ в поверхностной воде Каспийского моря в 1976 г. оценивается величиной 44 ТЕ (одна ТЕ соответствует одному атому ${ }^{3} \mathrm{H}$ на $10^{18}$ атомов ${ }^{1} \mathrm{H}$ ).

При условии полного отсутствия водообмена в глубинных $(h \geqslant 500$ м) водах Среднего и Южного Каспия в предположении имевшей место в 1976 г. полномасштабной вертикальной конвекции, достигшей дна в обеих котловинах, концентрация ${ }^{3} \mathrm{H}$ в этой водной массе должна была меняться только за счет радиоактивного распада по формуле

$$
C_{0}=C_{t} \mathrm{e}^{-\lambda t}
$$

$C_{0}$ - начальная концентрация ${ }^{3} \mathrm{H}, C_{t}-$ концентрация в момент времени $t, \lambda$ - постоянная распада, равная 0.05625 год $^{-1}$.

Используя в качестве $C_{t}$ средние концентрации ${ }^{3} \mathrm{H}$ в глубинных водах Среднего и Южного Каспия в 1996 г. [5] ( $t=20$ лет), можно оценить начальную концентрацию ${ }^{3} \mathrm{H}$ в поверхностной воде моря в 1976 г. $-C_{0}$ в формуле (2).

В глубинных водах Среднего Каспия $C_{t}=12 \mathrm{TE}$, чему соответствует $C_{0}=47 \mathrm{TE}$, для Южного Каспия соответствующие величины равны 7.6 и 23 ТЕ.

Приведенные расчеты показывают, что $C_{0}$ в формуле (2) для глубинных вод Среднего Каспия (47 ТЕ) близка к вычисленной по (1) концентрации ${ }^{3} \mathrm{H}$ в поверхностных водах Каспийского моря в 1976 г. (44 ТЕ ) и соответствует сценарию крупномасштабного вертикального водообмена в Среднем Каспии в этот год. В то же время $C_{0}$ для глубинных вод Южного Каспия (23 TЕ) существенно меньше, чем концентрация ${ }^{3} \mathrm{H}$ в поверхностных водах Каспийского моря в 1976 г., что подразумевает наличие в их составе более “старых" вод. Эти результаты также вписываются в первый сценарий крупномасштабного вертикального водообмена.

Перетекание растворенных фреонов из Среднего Каспия в Южный в процессе водообмена по первому сценарию также сопровождается изменением концентраций этих трассеров. Турбулентное перемешивание “старых" глубинных среднекаспийских вод с низким содержанием хлорфторуглеродов с поверхностными водами уменьшает их концентрацию в водах, перетекающих в глубинные слои Южного Каспия. С другой стороны, высокая концентрация хлорфторуглеродов в поверхностных горизонтах моря будет поддерживаться притоком хлорфторуглеродов из атмосферы. Следует иметь в виду, что поступление хлорфторуглеродов в морскую среду на фоне хронологической зависимости от их содержания в атмосфере имеет сезонную изменчивость, поскольку растворимость хлорфторуглеродов в воде сильно возрастает с уменьшением температуры воды.

Полагаем, что вышеизложенное достаточно убедительно свидетельствует в пользу первого 
сценария авторов [14], который предусматривал развитие крупномасштабной, достигшей дна гравитационной конвекции в Среднем Каспии в 1976 г. на границе кромки льда, сопровождаемой вентиляцией глубинных вод Южного Каспия за счет перетока “старых" среднекаспийских глубинных и промежуточных вод через Апшеронский порог, сформировавшей устойчивую вертикальную структуру глубинных водных масс Каспийского моря на два десятилетия.

\section{ВЫВОДЫ}

Проведенный анализ результатов международных изотопно-геохимических исследований в 1994-1996 гг. в Каспийском море с учетом доступных гидрометеорологических данных и особенностей датирования вод с помощью используемых преходящих трассеров (CFC-11, CFC-12, ${ }^{3} \mathrm{H}$ и $\left.{ }^{3} \mathrm{He}\right)$ позволил оценить их вклад в выявление особенностей формирования вертикальной структуры вод моря в период подъема его уровня, продолжавшегося с середины 1970-х до середины 1990-х гг. Вертикальное распределение преходящих трассеров характеризуется однородным их содержанием в глубинных водных массах $(h>500$ м). Распределение изотопных и химических трассеров в водных массах Каспийского моря позволило сделать вывод, что после крупномасштабной гравитационной конвекции в Среднем Каспии, вызванной аномальным охлаждением поверхностных вод в Северном Каспии в конце зимы 1976 г., сформировалась устойчивая структура глубинных водных масс (> 500 м) вплоть до полного прекращения вентиляции глубинных вод в Среднем и Южном Каспии до середины 1990-х гг. Различие процессов вертикального водообмена в Среднем и Южном Каспии (гравитационная конвекция в Среднем и турбулентное перемешивание в Южном) ограничивает возможность надежного определения возраста глубинных вод Южного Каспия на основе вертикального распределения преходящих трассеров в модели с единственным источником поступления преходящих трассеров в водные массы.

\section{СПИСОК ЛИТЕРАТУРЫ}

1. Брезгунов В.С., Ферронский В.И. Природный тритий как индикатор перестройки вертикальной структуры водных масс Каспийского моря при колебаниях его уровня // Вод. ресурсы. 2005. Т. 32. № 4. С. 406-409.
2. Данные климатического мониторинга // http:// seakc.meteoinfo.ru/actuals.

3. КАСПКОМ. Каталог температуры воды Каспийского моря // http://www.caspcom.com/index. php? razd= proj\&lang $=1$.

4. Косарев А.Н., Никонова Р.Е. Современные колебания уровня Каспийского моря: причины, последствия, тенденции // Вестн. Каспия. 2006. № 4. C. $40-59$.

5. Романов B.B. Применение природного трития для изучения перемешивания морских и речных вод // Вод. ресурсы. 1983. № 1. С. 130-144.

6. Тужслкин В.С., Гончаров А.В. О вентиляции глубинных вод Каспийского моря // Исследование океанов и морей. Тр. ГОИН. Вып. 211. 2008. С. 43-64.

7. Тужилкин В.С., Косарев А.Н. Многолетняя изменчивость вертикальной термохалинной структуры вод глубоководных частей Каспийского моря // Вод. ресурсы. Т. 31. № 4. 2004. С. 414-421.

8. Тужилкин В.С., Косарев А.Н., Архипкин В.С., Никонова P.E. Многолетняя изменчивость гидрологического режима Каспийского моря в связи с вариациями климата. // Вест. Моск. ун-та. Сер. 5, География. 2011. № 5. С. 62-71.

9. Ферронский В.И., Брезгунов В.С., Власова Л.С., Поляков., В.А., Романов В.В., Фрелих К., Ружанский К. Исследование водообменных процессов в Каспийском море на основе изотопных и океанографических данных // Вод. ресурсы. 2003. Т. 30. № 1. C. $15-28$.

10. Beining P., Roether $W$. Temporal evolution of CFC 11 and CFC 12 concentrations in the ocean interior // J. Geophys. Res. 1996. V. 101. P. 16455-16464.

11. Froehlich K., Imboden D., Kipfer R., Rozansky K. Dynamics of the Caspian Sea: Preliminary results of isotope studies // Proc. Symp. IAEA: Isotope Techniques in the Study of Environ. Change. Vienna, 1998. P. 249-264.

12. Kosarev, A.N., Yablonskaya, E.A. The Caspian Sea. The Hague: SPB Acad. Publ., 1994. 274 p.

13. Michel R.L., Suess H.E. Tritium in the Caspian Sea // Earth and Planet Sci. Lett. 1978. V. 39. № 3. P. 309-312.

14. Peeters F., Kipfer R., Achermann D., Hofer M., Aeschbach-Hertig W., Beyerle U., Imboden D.M., Rozanski K., Fröhlich $K$. Analysis of deep-water exchange in the Caspian Sea based on environmental tracers // Deep Sea Res. 2000. V. 47. P. 621-654.

15. Tsimitri C., Rockel B., Wuest A., Budnev N.M., Sturm M., Schmid M. Drivers of deep-water renewal events observed over 13 years in the South Basin of Lake Baikal. // J. Geophys. Res. Oceans. 2015. V. 120. P. 1508-1526.

16. Waugh D.W., Vollme M.K., Weiss R.F., Haine T.W.N., Hall T.M. Transit time distributions in Lake Issyk-Kul // Geoph. Res. Lett. 2002. V. 29. № 24. P. 84-1-84-4.

17. Weiss R.F. Helium isotope effect in solution in water and seawater // Sci. 1970. V. 168. P. 247-248. 


\title{
SPECIALTY OF VERTICAL WATER EXCHANGE OF THE CASPIAN SEA ON THE BASIS OF DISTRIBUTION OF TRANSIENT TRACERS
}

\author{
(C) 2019 V. S. Brezgunov ${ }^{1, *}$ \\ ${ }^{1}$ Institute of Water Problems of the Russian Academy of Sciences \\ Russia 119991 Moscow \\ *e-mail: brez@iwp.ru \\ Received: 01.02.2018 \\ Revised version received: 19.02.2019 \\ Accepted: 11.04.2019
}

The analysis of the reliability of different scenarios for the formation of the vertical structure of the waters of the Caspian Sea, obtained from the distribution of transient tracers (CFC-11, CFC-12, ${ }^{3} \mathrm{H}$ and ${ }^{3} \mathrm{He}$ ) at the deep-water stations of the Middle and Southern Caspian within the framework of international integrated isotope-geochemical studies during the maximum sea level rise in 1995-1996. Taking into account the available hydrometeorological data and the characteristics of water dating using transient tracers, it was concluded that after large-scale gravitational convection in the Middle Caspian caused by anomalous cooling of surface waters in the Northern Caspian at the end of the winter of 1976, a structure of water masses was formed that excluded deep water ventilation in the Middle and South Caspian Sea until the mid-90s.

Keywords: Caspian Sea, vertical water exchange, transient tracers.

DOI: $10.31857 /$ S0321-0596465496-502 